\title{
Intrathyroid Thymus in Adults: Heterotopia or Metaplasia? Handra-Luca A
}

Department of Pathology, GHU Avicenne, Universite Paris Sorbonne Cite, 125 Rue Stalingrad, 93009 Bobigny, deck 52047, 55601 secretariat, France

*Corresponding author: Handra-Luca A, Department of Pathology, GHU Avicenne, Universite Paris Sorbonne Cite, 125 Rue Stalingrad, 93009 Bobigny, deck 52047, 55601 secretariat, France; Tel: 0033148955555; Fax: 003314895555602/55480; E-mail: adriana.handra-luca@aphp.fr, adriana.handra-luca@hotmail.com

Received date: Oct 02, 2015; Accepted date: Jan 18, 2016; Published date: Jan 20, 2016

Copyright: ( 2016 Handra-Luca A. This is an open-access article distributed under the terms of the Creative Commons Attribution License, which permits unrestricted use, distribution, and reproduction in any medium, provided the original author and source are credited.

\section{Commentary}

Intrathyroid thymus in adults is rare, frequently revealed by neoplastic thymic-tissue derived tumors or cysts [1-3]. Kim et al. [2] reported recently one case in which the thymic tissue was clinically detected as a nodule in a 29 -years old woman with a previously surgically resected thyroid papillary carcinoma.

We have recently encountered another diagnosis instance for intrathyroid thymic tissue, that of incidentaloma in a thyroid resected for an autoimmune thyroidopathy of Graves-Basedow type.

The patient (woman, 36-years), diagnosed with hyperthyroidism in the context of Graves disease, presented with discomfort at deglutition. The thyroidectomy specimen showed a nodular pattern on macroscopy while microscopy revealed fibrosis and adenoma-type nodules. Intrathyroid striated muscle and adipocyte involution were also observed. Thyroid lymphocytic foci (more than 25) were observed as well as parathyroid tissue in intra- and perithyroid locations. Serial sections revealed in one of the lymphocytic foci, Hassall's corpuscles suggestive of thymic tissue (present on 2 of the 7 sections of the respective block). The thymic tissue (measuring 0.5-1.5 mm) was in part at contact to thyroid follicles, in part to adipose tissue. No capsule was observed. The P63 protein (immunohistochemistry performed on 2 different slides of which one with the thymic tissue) revealed only disperse positive nuclei in the thymic nodule and was negative in the lymphocytic foci. Cytokeratin AE1/AE3 was expressed in disperse epithelial cells in the thymic nodule while CD5 by several lymphocytes.

The clinical relevance of the diagnosis of incidental, microscopic intrathyroid thymus in the present case was limited. A microscopic thymoma or thymic carcinoma have to be ruled out. Although reported in pediatric cases [4], congenital cardiac abnormalities and other ectopic thymus sites should be probably considered in further investigations also in adult patients. The histogenesis of intrathyroid thymic tissue remains matter of debate. The widely accepted hypothesis of a thymus-migration abnormality is sustained in the present case by the presence of other intrathyroid ectopia-type lesions such as intrathyroid parathyroid and striated muscle. Interestingly, patients with autoimmune thyroid diseases, including Graves disease as in the present case, show higher intrathyroid T-receptor-excisioncircle, a marker of recent-thymic-emigrants, than controls [5]. Moreover, well-formed thyroid-associated ectopic thymic tissue is reported in Wistar rats after high iodine intake [6]. Therefore the lack of capsule along with the contact between thyroid vesicles and thymic lymphocytic tissue noted in the case we report may rather suggest a metaplastic nature. Whether the presence of Hassall's corpuscles and p63-positive cells in this thymic focus is the result of a stem cell differentiation or adult cell transdifferentiation process or not, remains to be further studied. Of interest would be the observation that isolated thyrocytes in goiter nodules may express p63 [7]. However this finding, rather suggesting a thyrocyte transdifferentiation to a p63-positive immunophenotype, remains incompletely understood to our knowledge (Figure 1).
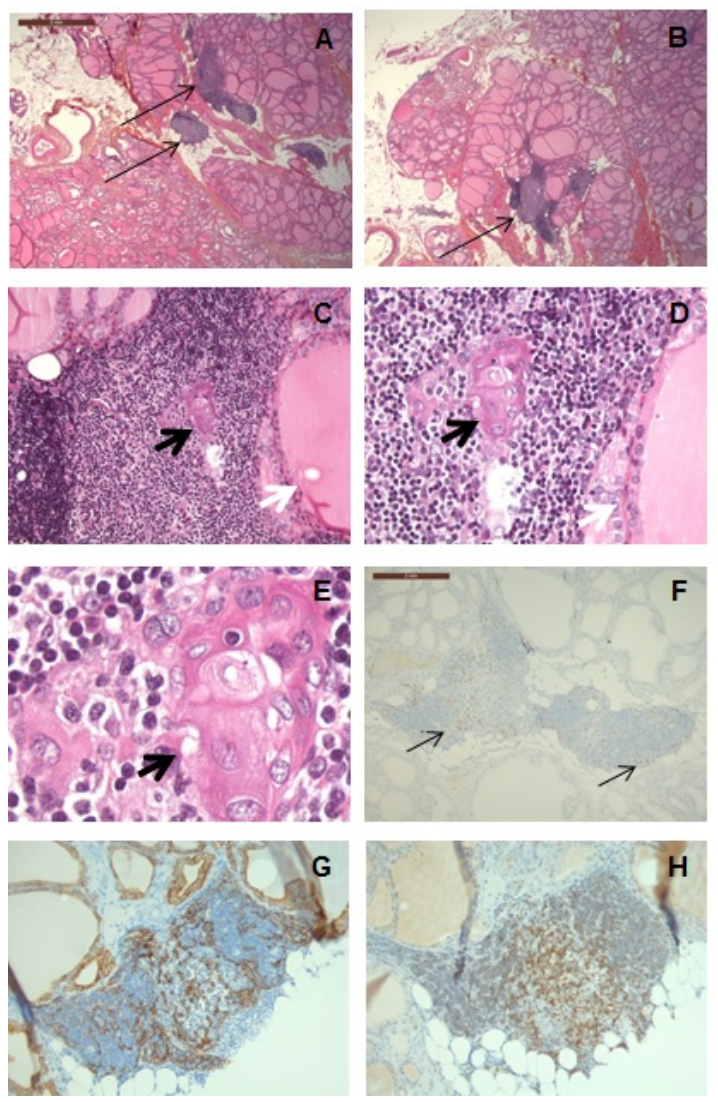

Figure 1: The thymic tissue was situated at contact to the thyroid (A,B: arrows, images from multistep sections). Thyroid vesicles were at close proximity to thymic lymphoid and Hassall's corpuscles (without fibrous tissue interposition) (C,D,E: black arrow/Hassall's corpuscle; white arrow/thyroid follicles). p63 was positive in dispersed intrathymic cells (F, arrows). Cytokeratin AE1/AE3 was expressed by sparse cells in a reticular or small-foci pattern, while CD5 in several lymphocytes. Hematoxilin and eosin stain (A-E), p63 (F), cytokeratin CKAE1/AE3 (G) and CD5 (H) immunohistochemistries; original magnification X2.5(A,B), X5(F), X10(C), X20(G,H), X40(D), X100(E).

In conclusion, we report a case of intrathyroid thymus detected incidentally on microscopic examination of a thyroid resection 
Citation: Handra-Luca A (2016) Intrathyroid Thymus in Adults: Heterotopia or Metaplasia?. J Cytol Histol 7: 389. doi:

Page 2 of 2

specimen for hyperthyroid Graves disease. The presence of direct contact between thyroid follicles and thymic tissue and lack of capsule may suggest a metaplastic origin in addition to that of migration abnormality.

\section{References}

1. Gilmour JR (1941) Some developmental abnormalities of the thymus and parathyroid. Journal of Pathology and Bacteriology 52: 213-218.

2. Kim A, Kang SH, Bae YK (2014) Ectopic intrathyroidal thymus accompanied by intrathyroidal parathyroid as a cause of a solitary thyroid nodule in adult. Int J Clin Exp Pathol 7: 6375-6378.

3. Rosai J (2011) Rosai and Ackerman's Surgical Pathology. Expert Consult. Mosby Elsevier; Philadelphia, PA.
4. Courcoutsakis N, Patronas N, Filie AC, Carney JA, Moraitis A, et al. (2009) Ectopic thymus presenting as a thyroid nodule in a patient with the Carney complex. Thyroid 19: 293-236.

5. Armengol MP, Sabater L, Fernández M, Ruíz M, Alonso N, et al. (2008) Influx of recent thymic emigrants into autoimmune thyroid disease glands in humans. Clin Exp Immunol 153: 338-350.

6. Mooij P, de Wit HJ, Drexhage HA (1994) A high iodine intake in Wistar rats results in the development of a thyroid-associated ectopic thymic tissue and is accompanied by a low thyroid autoimmune reactivity. Immunology 81: 309-316.

7. Handra-Luca A (2016) Expression patterns of cytokeratin 5/6 and p63 in thyroid sporadic nodular goiter. Min Endocrin (in press). 